\title{
1,25-dihydroxyvitamin D3 inhibits thyroid hormone-induced osteocalcin expression in mouse osteoblast-like cells via a thyroid hormone response element
}

\author{
F Varga, S Spitzer, M Rumpler and K Klaushofer \\ Ludwig Boltzmann Institute of Osteology, Fourth Medical Department, Hanusch Hospital, A-1140 Vienna, Austria \\ (Requests for offprints should be addressed to K Klaushofer, Ludwig Boltzmann Institute of Osteology, Fourth Medical Department, Hanusch Hospital, \\ Heinrich Collin-Str. 30, A-1140 Vienna, Austria; Email: Klaus.Klaushofer@univie.ac.at)
}

\begin{abstract}
Thyroid hormones are important regulators of bone development and metabolism. We have demonstrated that tri-iodothyronine (T3) increased and 1,25-dihydroxyvitamin D3 (1,25D3) attenuated the T3-stimulated expression of osteocalcin (OCN) in the osteoblast-like cell line MC3T3-E1. By means of transfection of promoter-reporter gene constructs we investigated the basal and the regulated transcription of this gene by both hormones. We found that a $0.67 \mathrm{kbp}$ and a $1.3 \mathrm{kbp}$ fragment of the mouse OCN OG2 promoter containing two Runx2 binding sites were significantly more active than a smaller fragment containing only one Runx2 binding site. The longer promoter fragments showed a higher reporter gene expression when the transfected cells were treated with $10^{-7} \mathrm{M}$ T3. This expression was attenuated by $1,25 \mathrm{D} 3$ dose-dependently. These fragments contain a sequence homologue to the recently identified binding site for the 1,25D3 receptor (VDR) in the rat OCN promoter. Deletion of a part of the promoter containing this VDR response element-like sequence (VDRE) resulted in a higher basal expression but abrogated the regulation by $\mathrm{T} 3$ and 1,25D3. Electrophoretic mobility shift assays revealed that the deleted sequence was able to bind both in vitro-translated chicken thyroid hormone receptor (TR) and proteins from nuclear extracts that reacted with an antiserum against TR. From these data we conclude that the VDRE-like sequence of the OG2 promoter contains a thyroid hormone response element.
\end{abstract}

Journal of Molecular Endocrinology (2003) 30, 49-57

\section{Introduction}

Thyroid hormones are essential for development and maintenance of the skeleton (Mosekilde et al. 1990, Allain \& McGregor 1993) and regulate multiple bone cell functions (Klaushofer et al. 1995). The main non-collagenous protein of the bone matrix is osteocalcin (OCN). This protein is expressed by mature osteoblasts and its expression is highly regulated by many local and humoral factors. Interestingly, a species-linked difference between mouse and rat in the regulation of its expression by tri-iodothyronine (T3) and 1,25dihydroxyvitamin D3 $(1,25 \mathrm{D} 3)$ respectively has been observed. While T3 increases the mRNA levels of OCN in mouse osteoblasts (Varga et al.
1997), OCN expression responds only weakly to T3 in rat osteosarcoma cells (Williams et al. 1995, Gouveia et al. 2001). 1,25D3, however, increases the expression of OCN in human (Kerner et al. 1989) and rat osteoblasts (Chen et al. 1986, Williams et al. 1995), but inhibits its basal expression in mice (Zang et al. 1997). In rat osteoblasts, the stimulation of OCN expression by $1,25 \mathrm{D} 3$ is considered to be a direct effect on transcription, whereas the inhibitory effect on basal expression in mouse osteoblasts is mediated by an indirect mechanism. It was shown that $1,25 \mathrm{D} 3$ treatment of primary osteoblasts abolishes the binding of the osteoblast-specific activator of transcription Runx2 (Cbfa1, OSF2), which binds to OSE2 (Ducy \& Karsenty 1995), a critical 
osteoblast-specific cis-acting element present in both OGN promoters OG1 and OG2 (Zang et al. 1997) and other genes expressed in osteoblasts.

Steroid hormone receptors usually regulate gene expression by binding as a homodimer/ heterodimer to the respective response elements. A steroid hormone response element is defined as a DNA sequence which binds selectively the steroid hormone receptor. This sequence consists of two or more repeats ('sites'), which can be oriented directly or inversely. Deletion analysis of the rat OCN promoter has demonstrated that there is a $25 \mathrm{bp}$ 5 -flanking region of the coding sequence able to confer 1,25D3 responsiveness to either the native OCN promoter or a heterologous viral promoter (Demay et al. 1990). Recently, a 3-4-5 rule was postulated, which suggests that the distance between two homologue 'half-sites' of such response elements should be three nucleotides for the 1,25D3 receptor (VDR), four nucleotides for the thyroid hormone receptor (TR) and five nucleotides for the retinoic receptors (Umesono et al. 1991). Sequence comparison of the rat 1,25D3 response elements (VDRE) with the mouse OCN OG2 promoter revealed a homologue sequence that differs in 3 bp (Zang et al. 1997). This led us to the hypothesis that this element also confers T3 responsiveness to the mouse OCN promoter.

Using an electrophoretic mobility shift assay (EMSA) we demonstrate that this VDRE-like sequence of the OG2 promoter binds the TR $\alpha 1$. We further show by deletion analyses of transfected OG2 promoter-reporter-vector constructs that this sequence is important for the basal and the T3-regulated expression of OGN. Furthermore, we also found that 1,25D3 inhibited the T3-regulated expression of OCN, and we present evidence for an involvement of the VDRE-like sequence in this attenuation process.

\section{Material and methods}

\section{Cell culture}

MC3T3-E1 cells (kindly donated by Dr Kumegawa, Meikai University, Department of Oral Anatomy, Sakado, Japan), and MC3T3-E1 clone 30 (kindly donated by Dr Franceschi, Department of Periodontics, University of Michigan, USA), and rat osteosarcoma cells (ROS 17/2.8) were cultured in aMEM (Sigma), supplemented with $4.5 \mathrm{~g} / \mathrm{l}$ glucose, $5 \%$ fetal calf serum (FCS) (Sigma) and $30 \mu \mathrm{g} / \mathrm{ml}$ gentamycin (Sigma) at $37{ }^{\circ} \mathrm{C}$ under $5 \% \mathrm{CO}_{2}$ in humidified air. They were sub-cultured twice a week using 0.001\% pronase E (Roche) and 0.02\% EDTA in $\mathrm{Ca}^{2+}$ - and $\mathrm{Mg}^{2+}$-free PBS. To prevent a potential phenotypic drift during repeated sub-cultures the cells were not used more than 4 weeks after thawing.

\section{RNA extraction and Northern analysis}

For Northern analysis cells were seeded at a density of about 20000 cells $/ \mathrm{cm}^{2}$ and cultured in the medium described above. After 6 days of culture a medium change was performed and $24 \mathrm{~h}$ later cells were treated with or without $10^{-7} \mathrm{M} \mathrm{T}$ 3 or $10^{-8} \mathrm{M} 1,25 \mathrm{D} 3$ for $48 \mathrm{~h}$. RNA was isolated using TRIZOL reagent (Sigma) according to the supplier's suggestions. The total amount of RNA was estimated by measuring the absorption at $260 \mathrm{~nm}$ with a spectrophotometer. Northern hybridisation was performed by fractionating $10 \mu \mathrm{g}$ total RNA on a $1 \%$ agarose gel containing $2 \cdot 2 \mathrm{M}$ formaldehyde. After electrophoresis the gel was transferred to a nylon filter (NEN, Brussels, Belgium) with $20 \times \mathrm{SSC}(1 \times \mathrm{SSC}$ is $0 \cdot 15 \mathrm{M}$ sodium chloride and $0.015 \mathrm{M}$ sodium citrate). After baking the filter for $2 \mathrm{~h}$ at $80^{\circ} \mathrm{C}$, hybridisation was done overnight in $10 \%$ SDS, $1 \mathrm{M}$ sodium phosphate buffer $\mathrm{pH} 7 \cdot 4$, after $1 \mathrm{~h}$ prehybridisation in the same solution. For estimation of the amount of hybridised mRNA, the filters were exposed and evaluated in an InstantImager (Packard Instrument Company, Meridien, CT, USA). As hybridisation probe we used the mouse OGN cDNA (Geleste et al. 1986). As a control we hybridised the same Northern blots with an EcoRI cDNA fragment of the human ribosomal cDNA. The probes were labelled by multi-prime labelling according to the supplier's suggestions (Roche).

\section{Semiquantitative RT-PCR}

The RNA was isolated as described above and $1 \mu \mathrm{g}$ RNA was reverse transcribed by Moloney murine leukaemia virus reverse transcriptase (Invitrogen) with random primers. For PCR we used as primers for Runx2 5'-GAG GGG ACA AGT TCT ATC TGG A and 5'-GGT GGT CGG CGA TGA TCT $\mathrm{G}$ and for glyceraldehyde 3-phosphate dehydrogenase (GAPDH) 5'-CTG CAC CAC CAA CTG 
CTT AGG C and 5'-GTC CAC CAC CGT GTT GCT GTA G. Amplification was performed with RedTaq DNA-Polymerase (Sigma) with an initial denaturation step at $94{ }^{\circ} \mathrm{C}$ for 5 min and thereafter $1 \mathrm{~min}$ at $94^{\circ} \mathrm{C}, 2 \mathrm{~min}$ at $57^{\circ} \mathrm{C}$ and $2 \min$ at $72{ }^{\circ} \mathrm{C}$ (40 cycles) or $1 \mathrm{~min}$ at $94{ }^{\circ} \mathrm{C}, 2 \mathrm{~min}$ at $54^{\circ} \mathrm{C}$ and $2 \mathrm{~min}$ at $72{ }^{\circ} \mathrm{C}$ (25 cycles) respectively. The PCR fragments were resolved by $1 \%$ agarose gel electrophoresis.

\section{Vectors}

The $0.16 \mathrm{kbp}$ and the $1.3 \mathrm{kbp}$ promoter fragment of the OG2 OGN promoter (Ducy \& Karsenty 1995) were kindly provided by G Karsenty (Department of Molecular Genetics, University of Texas, Houston, TX, USA). All constructs were first cloned into the $\mathrm{KpnI} / \mathrm{XhoI}$ site of the pGL3 basic luciferase reporter vector. Due to an influence of $\mathrm{T} 3$ on the luciferase expression all constructs were sub-cloned into the KpnI/HindIII site of the SEAP2 basic vector (secreted form of the human placental alkaline phosphatase) (Clontech, Palo Alto, CA, USA). A 670 bp promoter fragment (pOG2-0.67) extending from +13 to -657 was constructed by PCR using the primers 5'-TGG TCG ACT TGT CTG T-3' and 5'-CGA AGA CGT GGC CGA G-3' (Ducy \& Karsenty 1995). The deletion was introduced by amplification of the pOG2-0.67 using two additional primers, 5'-CGC ACT GGA TGA GCA GAG CTG CGG TGG GGT TTG GCT CCG-3' and 5'-GGG AGG CAA AGG CGA GGG CAG GTG TGG TGA TGC AGT GGG-3' (pOG2 $\delta$ TRE). (TRE=thyroid response element.) All constructs were verified by automatic DNA sequencing (VBC-Genomics, Vienna, Austria).

\section{Transfection experiments}

Transfection experiments were performed in 48-well plates (Nunc, Roskilde, Denmark). Cells were seeded at a density of 36000 cells $/ \mathrm{cm}^{2}$ and cultured overnight. On the next day medium was removed and cells were transfected with both $0.25 \mu \mathrm{g}$ OCN promoter-vector construct and $0.25 \mu \mathrm{g}$ cDNA of the chicken $\mathrm{TR} \alpha$ (kindly provided by M Zenke, IMP, Vienna, Austria) in DOSPER (Roche), with a ratio of $1: 5$ in $120 \mu$ serum-free medium. On the next day the medium was changed to the culture medium described above.
Two days later medium was changed again to the same medium with or without $10^{-7} \mathrm{M}$ T3. Forty-eight hours later $50 \mu \mathrm{l}$ supernatant were removed and analysed for SEAP activity according to the supplier's suggestions (Roche). Chemoluminescence was measured in a TopCounter (Packard) and statistical analysis (ANOVA) was performed using the Statview 4.5 software package (Abacus Concepts Inc., Berkley, CA, USA).

\section{EMSA}

Oligonucleotides were commercially synthesised. We used the $40 \mathrm{bp}$ fragment 5'-TGG ACG CTG AAG TGG GGA AAT GAG GAC ATT ACT GAA CAC TCG CT from the mouse OGN OG2 promoter (located at -474 to -435 , GeneBank AC U66848) containing the homologue sequence to the VDRE from rat. As a positive control we used the rat growth hormone $(\mathrm{rGH}) 5^{\prime}$-TRE AAA GGT AAG A TCA GGG ACG TGA CGG CAG (Williams \& Brent 1995). The probes were labelled by polynucleotide kinase and $\left[\gamma_{-}{ }^{32} \mathrm{P}\right] \mathrm{ATP}$ and used at a concentration of $50 \mathrm{fM}$. The assay was performed in a volume of $20 \mu \mathrm{l}$ with about $5 \mu \mathrm{g}$ nuclear extracts (Dignam et al. 1983) from MC3T3-E1 cells, in $20 \mathrm{mM}$ Hepes, $80 \mathrm{mM} \mathrm{KCl}$, $0 \cdot 1 \%$ Nonidet NP-40, $1 \mathrm{mM}$ dithiothreitol, $2 \mu \mathrm{g} / \mathrm{ml}$ poly $\mathrm{dI} / \mathrm{dC}$. Alternatively, we used $4 \mu \mathrm{l}$ in vitro-translated TR from the chicken- $\operatorname{erbA}(\alpha)$ cDNA using the in vitro translation system from reticulocytes (Promega). The protein/DNA complexes were separated in a $4 \%$ polyacrylamide gel (acrylamide:bisacrylamide 80:1) run in $0.25 \times$ Tris-borate-EDTA. Gel shift immunoassay experiments were performed by incubating the protein/DNA complex with $1 \mu \mathrm{l}$ anti-thyroid hormone receptor antibody $(\mathrm{ABR}$, Golden, $\mathrm{CO}$, USA) for $30 \mathrm{~min}$. The gels were exposed to the InstantImager.

\section{RIA of OCN}

To estimate the concentration of OCN protein in the culture media we used a commercial RIA kit (Biomedical Technologies Inc., Stoughton, MA, USA). According to the supplier's description of the RIA, there is no cross-reaction with bovine OCN and the RIA did not detect any measurable OGN in the culture media. Cells were seeded at a density of 50000 cells $/ \mathrm{cm}^{2}$ in 96 -well culture plates in 
aMEM supplemented with 5\% FCS and cultured overnight. On the next day cultures were untreated

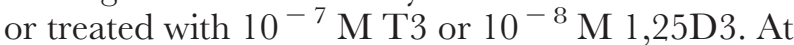
day 4 the culture media were removed and frozen. We performed single measurements of $10 \mu$ culture media from each well. The results are given as ng $\mathrm{OCN} / \mathrm{ml}$ culture media.

\section{Results}

As previously shown, T3 increases the expression of OCN in MC3T3-E1 osteoblast-like cells after a $24 \mathrm{~h}$ T3 treatment. This stimulation is time- and dose-dependent and depends on the cell density (Varga et al. 1997, 1999). The basal expression is inhibited by 1,25D3 (Zhang et al. 1997) and both this inhibition and the stimulation by $\mathrm{T} 3$ was transmitted to the protein level (Fig. 1A). Recently, several clones of the original MC3T3-E1 cell line were derived (Wang et al. 1999). MC3T3-E1 clone 30, in contrast to the original MC3T3-E1 cell line studied previously (Varga et al. 1997), expresses Runx2 at moderate levels (Fig. 1B) but just after seeding no OCN could be detected by Northern blot (Fig. 2). In this MC3T3-E1 clone, T3 also increased the expression of OCN (Fig. 2).

Sequence comparison of the mouse OG2 promoter with that of the rat revealed a homologue sequence to the rat VDRE that contained a putative TRE. This element consists of a conserved 'half-site' while the second one that is $4 \mathrm{bp}$ distant includes one mutation (Fig. 3A, notice the arrow) but should also bind $\mathrm{TR} \alpha 1$, although with reduced affinity (Judelson \& Privalsky 1996). We used this VDRE-like sequence with several base pairs flanking the $5^{\prime}$ and $3^{\prime}$ direction to perform EMSAs using either in vitro-translated TR (Fig. 4A) or nuclear extracts from MC3T3-E1 cells (Fig. 4B). The oligonucleotides containing the VDRE-like sequence bound both the in vitro-translated TR and the TR present in nuclear extracts of MC3T3-E1 cells. The latter was found to react with an antiserum against $\mathrm{TR} \alpha \mathrm{l}$ as demonstrated by a decrease of the electrophoretic mobility (Fig. 4B). Surprisingly the binding of the antibody seemed also to increase the affinity of the TR.

For transfection experiments we constructed several shortened fragments of the OG2 promoter and a $0.67 \mathrm{kbp}$ fragment with a deletion of the $40 \mathrm{bp}$ containing the VDRE-like sequence
A
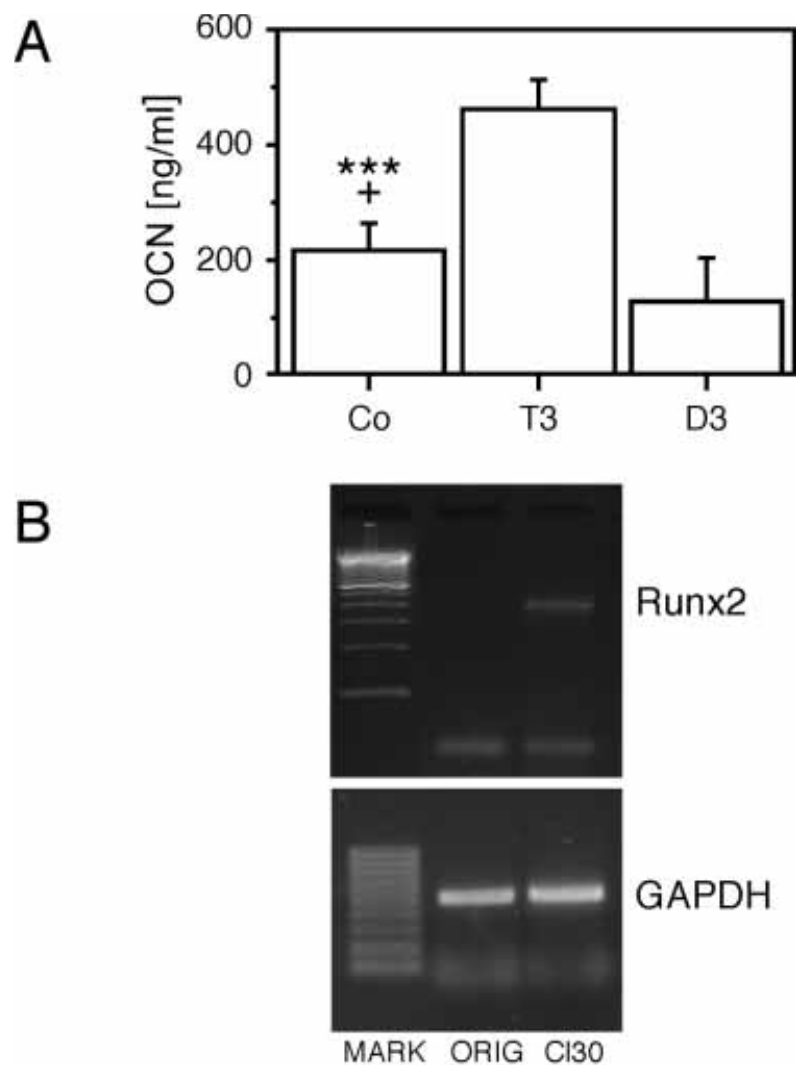

Figure 1 (A) Changes in expression of OCN mRNA were transduced to the protein level. MC3T3-E1 cells were seeded and cultured for 4 days. Thereafter the cultures were untreated (Co) or treated with $10^{-7} \mathrm{M}$ T3 or $10^{-8} \mathrm{M} \mathrm{D} 3$ for $24 \mathrm{~h}$. The bars represent the means \pm S.E.M. of the concentrations of $\mathrm{OCN}$ in the supernatants as measured with an RIA. $n=4$; ${ }^{* \star \star} P \leq 0.001$ (control vs T3 treatment); $+P=0.06$ (control vs $1,25 \mathrm{D} 3$ treatment). (B) The original MC3T3-E1 cell line (ORIG) did not show detected Runx2 mRNA levels while MC3T3-E1 clone $30(\mathrm{Cl} 30)$ expresses this transcription factor at moderate levels. mRNA isolated from both cell lines was reverse transcribed and amplified with specific primers either for Runx2 or for GAPDH as a control. The PCR products were separated on a $1 \%$ agarose gel (MARK: DNA length standard, $\lambda$ HindIII).

(Fig. 3B). After transfection of the $0 \cdot 16 \mathrm{kbp}$ OG2 fragment into original MC3T3-E1 cells we found a 2 -fold increase of the reporter gene transcription compared with the promoter-free (basic) vector (Fig. 5). The longer fragment $(0 \cdot 67 \mathrm{kbp})$ containing the VDRE-like sequence showed a $\sim 7$-fold increase while the $1.3 \mathrm{kbp}$ fragment displayed only a 4-fold increase of the reporter gene transcription. The deletion mutant ( $\delta$ TRE), however, showed the highest basal activity (Figs 5 and 6). 


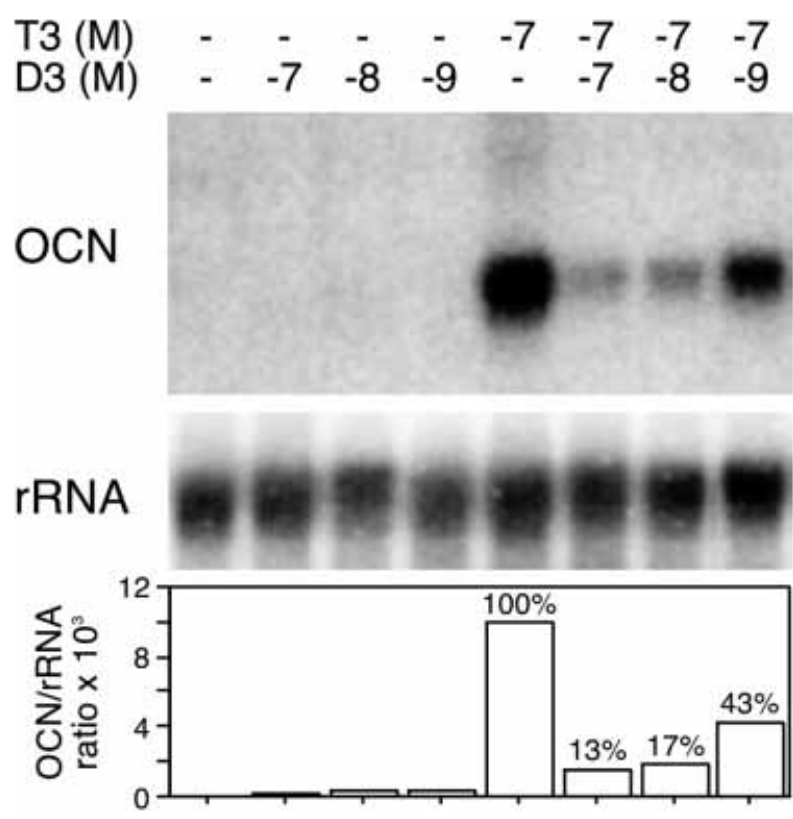

Figure 2 T3 increased and 1,25D3 dose-dependently attenuated the expression of OCN in mouse osteoblast-like cells. Northern blots of RNA isolated from untreated MC3T3-E1 cells clone $30(-)$ or cells treated with $10^{-7} \mathrm{M}$ T3 alone or in combination with the indicated concentrations of D3 for $48 \mathrm{~h}$ are shown. Control hybridisation was performed using a human ribosomal cDNA probe. After hybridisation the blots were exposed to an Instantlmager. The picture is a graphical representation of the counted radioactivity. The bars represent the counted radiation of OCN normalised to rRNA. The numbers above the bars indicate the inhibition of the T3-induced OCN mRNA $(100 \%)$ expression by D3.

In the original MC3T3-E1 cells, treatment of these transfections with $\mathrm{T} 3$ for $48 \mathrm{~h}$ resulted in no increase of the reporter gene transcription, either of the basic vector, indicating no influence of T3 on the assay system, or of the smallest fragment, indicating that there was no response element in this short promoter fragment (Fig. 5). Both the $0.67 \mathrm{kbp}$ fragment and the $1.3 \mathrm{kbp}$ fragment responded with a 2.5- or 3-fold increase of the transcription after $48 \mathrm{~h}$ of treatment with T3. The promoter fragment which lacks that part of the promoter containing the VDRE-like sequence ( $\delta \mathrm{TRE}$ ) showing the highest basal expression, did not respond to T3 treatment, indicating that the deleted sequence is important for repression of the basal as well as the T3-stimulated OCN expression (Fig. 5).

It was found that 1,25D3 inhibited the basal expression of OCN in mouse osteoblasts (Fig. 1A;
A

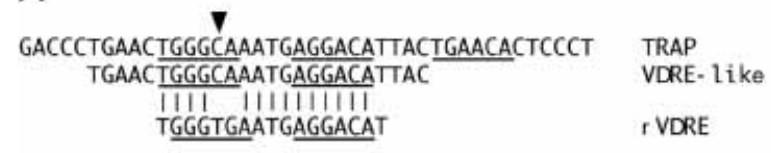

B

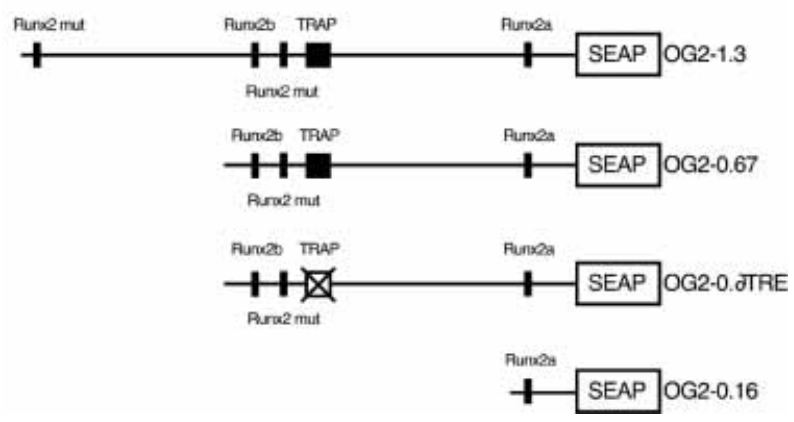

Figure 3 (A) Comparison of the mouse VDRE-like sequence and the rat VDRE ( $\mathrm{VDDRE}$ ) and the sequence that was deleted in the OG2- $\delta$ TRE reporter gene construct (TRAP). The putative TRE 'half-sites' and the VDRE are underlined. The arrow indicates that base pair which reduces the affinity of the TRE (Judelson \& Privalsky 1996). (B) Graphical representation of the used OG2 promoter SEAP reporter-vector constructs. Indicated are the locations of the VDRE-like sequence (TRAP) that was deleted and both the functional and the mutated Runx2 binding sites.

Zhang et al. 1997). This prompted us to test whether $1,25 \mathrm{D} 3$ could also attenuate the T3-stimulated OCN expression. Figure 2 shows that 1,25D3 dose-dependently attenuated the T3-induced OCN expression as similarly found in the original MC3T3-E1 cells (data not shown). Transfection of the $0.67 \mathrm{kbp}$ fragment into MC3T3-E1 clone 30 and treatment with $\mathrm{T} 3$ resulted in a 4-fold increase of the reporter gene transcription and as found with Northern blot 1,25D3 dose-dependently attenuated this transcription (Fig. 6A). Transfection of the $\delta$ TRE construct into MC3T3-E1 clone 30 yielded also an increase of the basal transcription as found with original MC3T3-E1 cells (Figs 5 and 6B). Treatment of these transfected cultures with $\mathrm{T} 3$ or with both $\mathrm{T} 3$ and 1,25D 3 resulted in a tendency to decrease the basal transcription (Fig. 6B) but the effects were statistically not significant.

\section{Discussion}

By means of transfection experiments we have shown that the part of the mouse OG2 promoter 


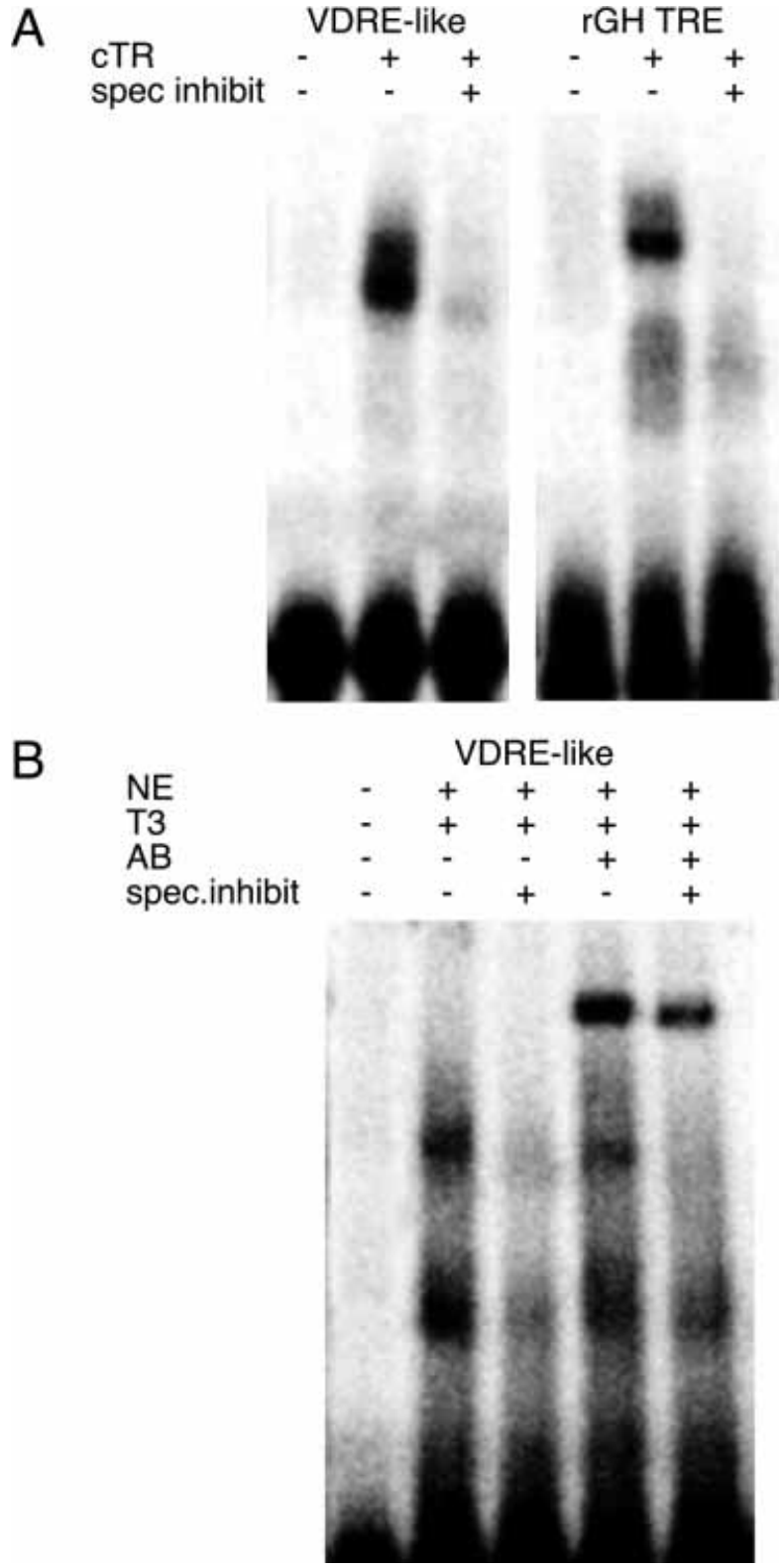

Figure $4(A)$ EMSA of the VDRE-like sequence of the mouse OCN promoter and the TRE from the $\mathrm{rGH}$ promoter with in vitro-translated chicken c-erbA $(\alpha)$ receptor (cTR). Specific competition of the binding was performed with a 100-fold excess of unlabelled oligonucleotide (spec inhibit). (B) EMSA of the VDRE-like sequence of the mouse OCN promoter with nuclear extracts (NE) isolated from MC3T3-E1 cells. Supershift was performed by preincubation of the reaction mixture with $2 \mu$ lantiserum against TR $(A B)$. Specific competition of the binding was performed using a 100-fold excess of unlabelled oligonucleotide (spec inhibit). T3 indicates that during the assay $10^{-7} \mathrm{M} \mathrm{T3}$ was present.

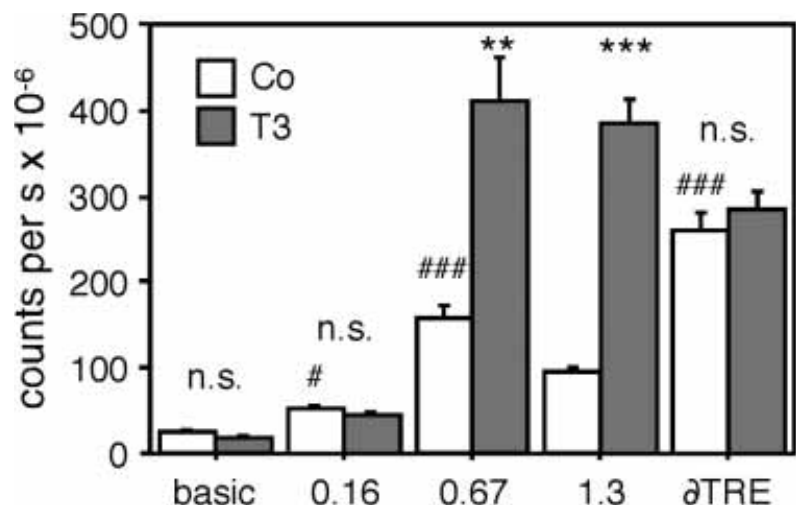

Figure 5 Effects of the deletions of the $5^{\prime}$ end and the VDRE-like sequence of the OG2 promoter on its basal activity and T3 inducibility. Measurements of the SEA $\mathrm{P}$-activity in culture supernatants transfected with the indicated OG-2 promoter-vector constructs and chicken c-erbA $(\alpha)$ into original MC3T3-E1 cells after $48 \mathrm{~h}$ treatment without (Co) or with $10^{-7} \mathrm{M}$ T3. Bars represent the means \pm S.E.M. from four cultures. $\# P \leq 0.05$; \#\#\#P 0.001 (OG2-containing vector vs basic vector). ${ }^{* *} P \leq 0.01 ;{ }^{* *} P \leq 0.001$ (treatment vs control).

containing a sequence which is a homologue to the VDRE of the rat OCN promoter was important for the T3 regulation of the mouse OCN expression but also for the inhibition by 1,25D3. We have further shown that this part of the promoter also bound the TR. In addition, we found that the longer promoter fragment with $0.67 \mathrm{kbp}$, containing both Runx2 binding sites, had a much higher basal activity than the truncated one $(0 \cdot 16 \mathrm{kbp})$ containing only the proximal Runx2a binding place. But surprisingly, this seemed to be independent of Runx2 because the transfected promoter-reporter gene constructs showed a comparable basal and T3-dependent expression whether transfected into the Runx2expressing MC3T3-E1 clone 30 or into the original MC3T3-E1 cells that express no Runx2. One explanation of this contradictory result could be that, although not detected by PCR, the original MC3T3-E1 cells express enough Runx2 protein to enable basal expression of the reporter gene expression. This explanation, although not very likely, could also explain the higher expression of the constructs containing two Runx2 binding sites. Otherwise, we have to postulate other transcription factors (Ducy \& Karsenty 1995) or homologues of Runx2 or yet unidentified splicing variants. 
A

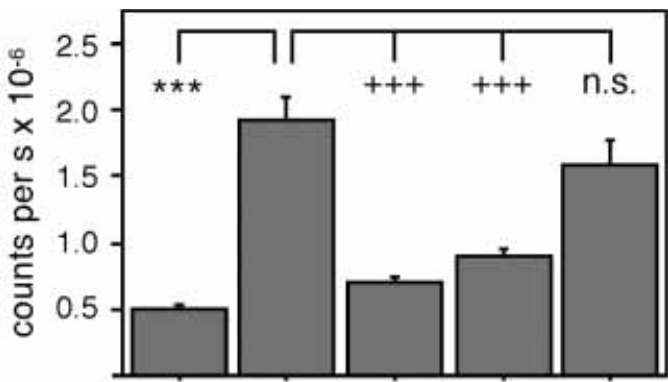

B

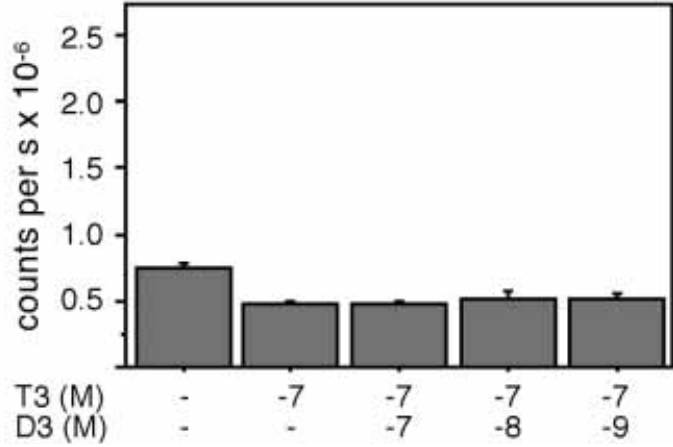

Figure 6 Effects of T3 and 1,25D3 or both on reporter gene expression of (A) OG2-0.67 and (B) on OG2- $\delta$ TRE. Measurements of the SEAP-activity in culture supernatants transfected with the indicated OG-2 promoter-vector constructs and chicken c-erbA $(\alpha)$ into MC3T3-E1 clone 30 after $48 \mathrm{~h}$ treatment without $(-)$ or with $10^{-7}$ M T3 (T3) alone or in combination with the indicated concentrations of 1,25D3 (D3). Bars represent the means \pm S.E.M. from four cultures. ${ }^{* \star *} P \leq 0.001$ (untreated vs T3 treatment). $+++P \leq 0.001$ (T3 treatment vs treatment with T3 and 1,25D3).

Recently, it was published that the functional Runx2 sites found in the OG2 promoter, contribute differentially to the basal OCN expression (Frendo et al. 1998). The Runx2a site next to the transcription start located between -137 and -131 was described as being more important for bone-specific transcription from the OG2 promoter than the more distally located Runx2b site at -608 to -602 . A mutation of the Runx2a binding site results in a strong decrease of the reporter gene transcription but the mutation of the Runx2b site results only in a marginal decrease. Similar results were found in transgenes carrying these mutated reporter gene constructs (Frendo et al. 1998). The difference between our findings and those of Frendo et al. (1998) in the contribution of the Runx2a and Runx2b binding sites of the OG2 promoter to the basal reporter gene transcription could be due to other binding sites for transcription factors upstream from the Runx2a site, and deletion of this upstream region could abolish the interaction with Runx2 protein resulting in a reduced basal expression from this short promoter fragment.

In the rat OGN promoter a VDRE was identified which could be also found in the mouse OGN OG2 promoter, although with three nucleotides changed. Deletion of this VDRE-like sequence of the OG2 promoter resulted in a reporter gene expression between the basal and T3-stimulated expression in both cell lines studied. The TR, unlike other classical steroid receptors, is able to bind to the TREs in the absence of the hormone and mediates a decrease of basal expression. In the presence of its ligand, TR binds specifically to the TRE of genes and induces their expression (Brent et al. 1989, Graupner et al. 1989). In common with the fact that an oligonucleotide containing the rat VDRE-like sequence bound in vitro-translated $\mathrm{TR} \alpha \mathrm{l}$ we can conclude that this DNA fragment behaves like a typical TRE (Williams \& Brent 1995). The VDRE-like sequence, which is a homologue to the VDRE in the rat OCN promoter that is important for 1,25D3-regulated OCN expression in rat osteoblasts, could also be interpreted as a TRE consisting of two 'half-sites' separated by four nucleotides. However, while the $3^{\prime}$ 'half-site' is well conserved the second one located $4 \mathrm{bp}$ distant contains one base pair which reduces binding of TRs (Judelson \& Privalsky 1996). This could explain the relatively weak interaction found in the EMSA. Interestingly, addition of the antibody resulted in an obvious increase in binding of the TR isolated from nuclear extracts. Interaction of a receptor with its response element depends on the affinity of both partners. Change of affinity could be achieved by either changing the nucleotide sequence of the response elements (Katz et al. 1995, Judelson \& Privalsky 1996, Staal et al. 1996) or change of the conformation of the receptor protein as often found in mutated receptors. This opens a field for a wide variation of modulation for such an interaction. Variation of the nucleotide composition and the distance of 'half sites' of the response elements determines not only the type of the binding receptor (Kato et al. 1995, Klinge et al. 1997) but can also change the conformation of the receptor protein and from that the change of the antigenic determinants as found with a set of antibodies against the VDR (Staal et al. 1996). Such 
a change could also modulate the set of accessory proteins interacting with the steroid receptors (Seol et al. 1995, Hollenberg et al. 1996). The binding of accessory proteins could also change the conformation and therefore the affinity as recently described for the oestrogen receptor (Romine et al. 1998). The antibody used in our experiments could substitute for such a protein. This would explain the increase in the binding affinity of TR to the TRE as found in the EMSA.

Interestingly, T3 did not induce a reporter gene construct containing the rat OCN gene 5'-flanking region (to $-1750 \mathrm{bp}$ ) or the previously described rat OCN VDRE when transfected into ROS $17 / 2 \cdot 8$ cells in spite of the high homology between the rat VDRE and the putative TRE in mouse (Gouveia et al. 2001). Multiple Runx2 binding sites are required for basal and 1,25D3-responsive transcription (Javed et al. 1999). The different distribution of the Runx2 binding sites (Ducy \& Karsenty 1995) and hence a different preferred formation of complexes of steroid receptors with Runx2 could be responsible for this speciesdependent difference in the regulation of OGN expression. But as mentioned, instead of Runx2 other accessory proteins could be important.

The difference of the nucleotide sequence could also be responsible for the species difference in the regulation of OCN expression between rat and mouse as it has been found that no VDR binds to the VDRE-like sequence in mouse OG2 promoter. Moreover, it was found that 1,25D3 inhibited OCN expression in mouse osteoblasts by an indirect mechanism (Zhang et al. 1997). These authors found that mutation of the Runx2a site resulted in an abrogation of the 1,25D3 inhibition of the basal expression of a reporter gene construct. We found that 1,25D3 also attenuated T3-induced OCN transcription as found with Northern blots in both the original MC3T3-E1 cell line (data not shown) and MC3T3-E1 clone 30. Transfection of OG2-0.67 kb reporter gene constructs into the latter cell line resulted in an increase of the transcription and 1,25D3 dose-dependently attenuated this transcription. Deletion of the sequence containing the postulated TRE (OG2- $\delta$ TRE) resulted in an abrogation of the dose-dependent regulation by both T3 and 1,25D3. Furthermore, both hormones reduced the basal expression, although not significantly. These data suggest a different mechanism between the basal and the
T3-regulated OCN expression because T3 did not regulate Runx2 expression (data not shown). While a direct interaction of TR and VDR by binding is discussed controversially, a regulatory cross-talk was found (Yen et al. 1996). Depending on the sequence of the response elements, binding of VDR/retinoid X receptors heterodimers to TREs can modulate T3-mediated transcription. Not surprisingly, the inverse mechanism that TRs can also repress VDR-mediated transcription was also found with reporter gene constructs of the rat OCN and rat 24-hydroxylase promoter (Raval-Pandya et al. 1998). Further studies will reveal these regulatory interactions between 1,25D3 and T3 in the regulation of OCN expression and the obscure species difference.

In summary, we have shown that a part of the mouse OG2 promoter containing a rat VDRE-like sequence was able to bind the TR $\alpha 1$ and functions as a TRE in a reporter gene assay. 1,25D3 attenuated the transcription from this promoter possibly by a mechanism different from its effect on basal transcription. We further found that this regulation could be abolished by deletion of that part of the promoter containing the postulated TRE. Being aware that deletion of this sequence could change the conformation of the DNA and influence the regulatory behaviour of the promoter, our data suggest that T3 regulates the expression of OCN by increasing its transcription via binding to a TRE, located in the OG2 promoter.

\section{References}

Allain TJ \& McGregor AM 1993 Thyroid hormones and bone. Fournal of Endocrinology 139 9-18.

Brent GA, Dunn MK, Harney JW, Gulick T, Larsen PR \& Moore DD 1989 Thyroid hormone aporeceptor represses T3-inducible promoters and blocks activity of the retinoic acid receptor. The New Biologist 1 329-336.

Celeste AJ, Rosen V, Buecker JL, Kriz R, Wang EA \& Wozney JM 1986 Isolation of the human gene for bone gla protein utilizing mouse and rat cDNA clones. EMBO fournal 5 1885-1890.

Chen TL, Hauschka PV, Cabrales S \& Feldman D 1986 The effects of 1,25-dihydroxyvitamin D3 and dexamethasone on rat osteoblast-like primary cell cultures: receptor occupancy and functional expression patterns for three different bioresponses. Endocrinology 118 250-259.

Demay MB, Gerardi JM, DeLuca HF \& Kronenberg HM 1990 DNA sequences in the rat osteocalcin gene that bind the 1,25-dihydroxyvitamin D3 receptor and confer responsiveness to 1,25-dihydroxyvitamin D3. PNAS 87 369-373.

Dignam JD, Lebovitz RM \& Roeder RG 1983 Accurate transcription initiation by RNA polymerase II in a soluble extract from isolated mammalian nuclei. Nucleic Acids Research 11 $1475-1489$. 
Ducy P \& Karsenty G 1995 Two distinct osteoblast-specific cis-acting elements control expression of a mouse osteocalcin gene. Molecular and Cellular Biology 15 1858-1869.

Frendo JL, Xiao G, Fuchs S, Franceschi RT, Karsenty G \& Ducy P 1998 Functional hierarchy between two OSE2 elements in the control of osteocalcin gene expression in vivo. Fournal of Biological Chemistry 273 30509-30516.

Gouveia CH, Schultz JJ, Bianco AC \& Brent GA 2001 Thyroid hormone stimulation of osteocalcin gene expression in ROS $17 / 2 \cdot 8$ cells is mediated by transcriptional and post-transcriptional mechanisms. Fournal of Endocrinology 170 667-675.

Graupner G, Wills KN, Tzukerman M, Zhang XK \& Pfahl M 1989 Dual regulatory role for thyroid-hormone receptors allows control of retinoic-acid receptor activity. Nature 340 653-656.

Hollenberg AN, Monden T, Madura JP, Lee K \& Wondisford FE 1996 Function of nuclear co-repressor protein on thyroid hormone response elements is regulated by the receptor A/B domain. Fournal of Biological Chemistry 271 28516-28520.

Javed A, Gutierrez S, Montecino M, van Wijnen AJ, Stein JL, Stein GS \& Lian JB 1999 Multiple Cbfa/AML sites in the rat osteocalcin promoter are required for basal and vitamin D-responsive transcription and contribute to chromatin organization. Molecular and Cellular Biology 19 7491-7500.

Judelson C \& Privalsky ML 1996 DNA recognition by normal and oncogenic thyroid hormone receptors. Unexpected diversity in half-site specificity controlled by non-zinc-finger determinants. Journal of Biological Chemistry 271 10800-10805.

Kato S, Sasaki H, Suzawa M, Masushige S, Tora L, Chambon P \& Gronemeyer H 1995 Widely spaced, directly repeated PuGGTCA elements act as promiscuous enhancers for different classes of nuclear receptors. Molecular and Cellular Biology 15 5858-5867.

Katz RW, Subauste JS \& Koenig RJ 1995 The interplay of half-site sequence and spacing on the activity of direct repeat thyroid hormone response elements. Fournal of Biological Chemistry $\mathbf{2 7 0}$ $5238-5242$.

Kerner SA, Scott RA \& Pike JW 1989 Sequence elements in the human osteocalcin gene confer basal activation and inducible response to hormonal vitamin D3. PNAS 86 4455-4459.

Klaushofer K, Varga F, Glantschnig H, Fratzl-Zelman N, Czerwenka E, Leis HJ, Koller K \& Peterlik M 1995 The regulatory role of thyroid hormones in bone cell growth and differentiation. Fournal of Nutrition 125 1996S-2003S.

Klinge CM, Bodenner DL, Desai D, Niles RM \& Traish AM 1997 Binding of type II nuclear receptors and estrogen receptor to full and half-site estrogen response elements in vitro. Nucleic Acids Research 25 1903-1912.

Mosekilde L, Eriksen EF \& Charles P 1990 Effects of thyroid hormones on bone and mineral metabolism. Endocrinology and Metabolism Clinics of North America 19 35-63.

Raval-Pandya M, Freedman LP, Li H \& Christakos S 1998 Thyroid hormone receptor does not heterodimerize with the vitamin D receptor but represses vitamin $\mathrm{D}$ receptor-mediated transactivation. Molecular Endocrinology 12 1367-1379.

Romine LE, Wood JR, Lamia LA, Prendergast P, Edwards DP \& Nardulli AM 1998 The high mobility group protein 1 enhances binding of the estrogen receptor DNA binding domain to the estrogen response element. Molecular Endocrinology $12664-674$.

Seol W, Choi HS \& Moore DD 1995 Isolation of proteins that interact specifically with the retinoid $\mathrm{X}$ receptor: two novel orphan receptors. Molecular Endocrinology 9 72-85.

Staal A, van Wijnen AJ, Birkenhager JC, Pols HA, Prahl J, DeLuca H, Gaub MP, Lian JB, Stein GS, van Leeuwen JP et al. 1996 Distinct conformations of vitamin D receptor/retinoid X receptor-alpha heterodimers are specified by dinucleotide differences in the vitamin D-responsive elements of the osteocalcin and osteopontin genes. Molecular Endocrinology 10 1444-1456.

Umesono K, Murakami KK, Thompson CC \& Evans RM 1991 Direct repeats as selective response elements for the thyroid hormone, retinoic acid, and vitamin D3 receptors. Cell 65 $1255-1266$.

Varga F, Rumpler M, Luegmayr E, Fratzl ZN, Glantschnig H \& Klaushofer K 1997 Triiodothyronine, a regulator of osteoblastic differentiation: depression of histone $\mathrm{H} 4$, attenuation of c-fos/c-jun, and induction of osteocalcin expression. Calcified Tissue International $61404-411$.

Varga F, Luegmayr E, Fratzl ZN, Glantschnig H, Ellinger A, Prinz D, Rumpler M \& Klaushofer K 1999 Tri-iodothyronine inhibits multilayer formation of the osteoblastic cell line, MC3T3-E1, by promoting apoptosis. Fournal of Endocrinology 160 57-65.

Wang D, Christensen K, Chawla K, Xiao G, Krebsbach PH \& Franceschi RT 1999 Isolation and characterization of MC3T3-E1 preosteoblast subclones with distinct in vitro and in vivo differentiation/mineralization potential. Fournal of Bone and Mineral Research 14 893-903.

Williams GR, Bland R \& Sheppard MC 1995 Retinoids modify regulation of endogenous gene expression by vitamin D3 and thyroid hormone in three osteosarcoma cell lines. Endocrinology 136 $4304-4314$.

Williams GR \& Brent GA 1995 Thyroid hormone response elements 217-239. In Molecular Endocrinology: Basic Concepts and Clinical Correlations. Ed. D Bruce. New York: Raven Press.

Yen PM, Liu Y, Sugawara A \& Chin WW 1996 Vitamin D receptors repress basal transcription and exert dominant negative activity on triiodothyronine-mediated transcriptional activity. Fournal of Biological Chemistry 271 10910-10916.

Zhang R, Ducy P \& Karsenty G 1997 1,25-dihydroxyvitamin D3 inhibits osteocalcin expression in mouse through an indirect mechanism. Fournal of Biological Chemistry 272 110-116.

Received in final form 3 July 2002 Accepted 19 September 2002 